\title{
Hydrophobic Polymeric Additives toward a Long-Term Robust Carbonaceous Mudstone Slope
}

\author{
Hongyuan Fu ${ }^{1,2, *}$, Caiying Chen ${ }^{1}\left(\right.$, , Huanyi Zha ${ }^{2}$, Du Yuan ${ }^{3}$, Qian-Feng Gao ${ }^{1}$, Ling Zeng ${ }^{2}$ and Chuankun Jia ${ }^{1, *}$ \\ 1 School of Traffic \& Transportation Engineering, Changsha University of Science \& Technology, \\ Changsha 410114, China; chency100_18@163.com (C.C.); qianfeng.gao@csust.edu.cn (Q.-F.G.) \\ 2 School of Civil Engineering, Changsha University of Science \& Technology, Changsha 410114, China; \\ zhahy0326@stu.csust.edu.cn (H.Z.); z1001@csust.edu.cn (L.Z.) \\ 3 College of Materials Science and Engineering, Changsha University of Science \& Technology, \\ Changsha 410114, China; aduyuandu@gmail.com \\ * Correspondence: fuhy001@csust.edu.cn (H.F.); jiachuankun@csust.edu.cn (C.J.)
}

Citation: $\mathrm{Fu}, \mathrm{H}$.; Chen, C.; Zha, H.; Yuan, D.; Gao, Q.-F.; Zeng, L.; Jia, C. Hydrophobic Polymeric Additives toward a Long-Term Robust Carbonaceous Mudstone Slope. Polymers 2021, 13, 802. https:// doi.org/10.3390/polym13050802

Academic Editor: Yun-Che Wang

Received: 10 February 2021

Accepted: 28 February 2021

Published: 5 March 2021

Publisher's Note: MDPI stays neutral with regard to jurisdictional claims in published maps and institutional affiliations.

Copyright: (c) 2021 by the authors. Licensee MDPI, Basel, Switzerland. This article is an open access article distributed under the terms and conditions of the Creative Commons Attribution (CC BY) license (https:// creativecommons.org/licenses/by/ $4.0 /)$.
Abstract: Slopes with carbonaceous mudstone (CM) are widely distributed in the southwest of China and have experienced numerous geological disasters in special climate, especially in rainfall conditions. Therefore, novel materials to stabilize $\mathrm{CM}$ slopes have attracted increasing interests. However, developing ultra-stable and cost-effective additives for CM slopes is still a great challenge. Herein, a hydrophobic polymeric material (polyvinylidene fluoride, PVDF) is investigated as an additive to enhance the mechanical strength and long-time stability of CM slopes. The PVDF is uniformly dispersed in CM matrix via interfacial interaction. The contact angle of the PVDFmodified carbonaceous mudstone (PVDF-MCM) can reach as high as $103.95^{\circ}$, indicating an excellent hydrophobicity. The unconfined compressive strength (UCS) and tensile strength (TS) of PVDF-MCM have been intensively enhanced to $4.07 \mathrm{MPa}$ and $1.96 \mathrm{MPa}$, respectively, compared with $\sim 0 \mathrm{MPa}$ of pristine CM. Moreover, the UCS and TS of PVDF-MCM remain at 3.24 MPa and 1.03 MPa even after curing for 28 days in high humidity conditions. Our findings show that the PVDF can improve the hydrophobicity of CM significantly, which leads to super mechanical stability of PVDF-MCM. The excellent performance makes PVDF a promising additive for the development of ultra-stable, long-lifetime and cost-effective carbonaceous mudstone slopes.

Keywords: carbonaceous mudstone; hydrophobic material; mechanical properties

\section{Introduction}

Uneven shrinkage, water-weakening effects, temperature effects, and mechanical changes are the main factors contributing to the damage of microstructures of rock blocks [1] Water plays a key role in mudstone disintegration [2]. The interaction between water and mudstone causes significant changes in physical and mechanical properties of the rock mass. Mechanical properties including the compressive strength of mudstone decrease with the extension of immersion time and gradually stabilize [3]. Carbonaceous mudstone (CM) is widely distributed in the southwest of China, where the annual precipitation in this region is typically 1200-2000 mm (e.g., in the year 2015) or even more [4]. CM shows disintegration when undergoing wetting-drying cycles and temperature change. After disintegration, its strength sharply drops with large wetting deformation and secondary disintegration continues. As a result, layered disintegration happens in CM from the outside towards the inside. Consequently, the disintegration results in massive waste of solid CMs. Due to the above, CM slopes easily show instability and collapse [5,6]. During the “Twelfth Five-Year Plan" period, 64,521 geological disasters (including collapses, landslides, mudslides, ground collapse, ground fissures, ground subsidence, etc.) occurred in China, resulting in 2008 deaths and missing people, 1317 injuries, and direct economic losses of 
27.34 billion RMB [7]. Therefore, research on the stability of mudstone slopes is critical and imperative.

Common methods for enhancing the stability of slopes include slope protection, anchors, anti-slide piles and comprehensive reinforcement methods [8-11], but none of them are based on improving the engineering performance of slope itself. Although traditional calcium-based rock and soil amendments (e.g., cement, lime, and fly ash) can effectively improve the strength and durability of slope, they may produce cracks and reduce the service life of slope [12-14]. Especially for the easy-to-disintegrate CM slope under the wetting-drying cycles, traditional calcium-based materials cannot effectively solve the layered disintegration phenomenon. For this reason, non-calcium-based materials including polymers and emulsions have been used as soil stabilizers to increase strengths, reduce soil liquefaction and permeability, and improve water and weathering resistances. For example, superabsorbent polymers have been used to improve the moisture sensitivity and the shear strength of subgrade soil [15]. Emulsions have been receiving increasing attention due to their good stability, low cost, and easy workability. Some emulsions such as methylene diphenyl diisocyanate, xanthan gum, styrene-acrylic emulsion, amphiphilic $\mathrm{O} / \mathrm{W}$ emulsions, water-based polyurethane, and bitumen emulsions are successfully used as additives to optimize the mechanical strength and other engineering properties of rock or sand slopes [16-22]. However, the above materials are mainly used to modify soils, where their applications on disintegrated CM are rarely reported. Polyvinylidene fluoride (PVDF) is a typical hydrophobic material, which is commonly used in water treatment, membrane distillation, gas separation, lithium-ion battery separators, composite membrane, and other fields, owing to its high thermal stability, good chemical properties, and strong film forming properties $[23,24]$.

In this work, the PVDF is proposed to modify carbonaceous mudstone. The unconfined compressive strength (UCS) and tensile strength (TS) (including durability) of the PVDF modified carbonaceous mudstone (PVDF-MCM) are investigated, with the characterizations of scanning electron microscopy (SEM), X-ray fluorescence (XRF), X-ray diffraction (XRD), and Fourier transform infrared spectroscopy (FTIR) tests. The relationship between the contact angle and strength of modified CM and the PVDF contents are evaluated qualitatively and quantitatively. Further, the interaction between PVDF and CM is discussed from the perspectives of microstructure and chemical analysis, where the interaction mechanism is proposed.

\section{Experimental Details}

\subsection{Materials}

CM was taken from the K18 + 500 site of the Liuzhai-Hechi Expressway in Guangxi. Previous tests showed that after disintegration under a certain vertical load and wet-dry cycles, the proportion of $\mathrm{CM}$ particles is smaller than $2 \mathrm{~mm}$ [5]. So, CM particles were dried at $106^{\circ} \mathrm{C}$ for $48 \mathrm{~h}$, then cooled to room temperature and passed through a $2 \mathrm{~mm}$ sieve. The particle-size distribution of CM is shown in Figure 1. The mineral composition of CM included quartz, kaolinite, mica, siderite, pyrite, etc., with mass fractions of 40.28 , $24.86,18.79,8.52,4.65$, and $2.9 \mathrm{wt} \%$, respectively. The maximum dry density, optimal moisture content, liquid limit, and plastic limit of the main physical parameters of $\mathrm{CM}$ were $2.08 \mathrm{~g} / \mathrm{cm}^{3}, 10.78,33.10$, and $25.20 \mathrm{wt} \%$, respectively. 


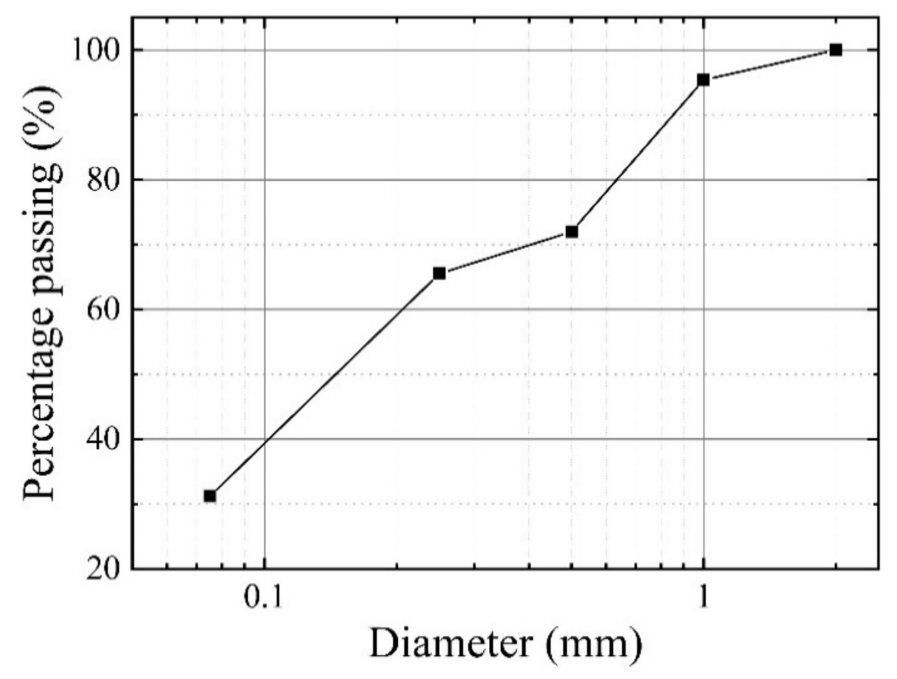

Figure 1. Size distribution of carbonaceous mudstone (CM) particles.

PVDF has the molecular formula of -(CH2-CF2 $)_{n}{ }^{-}$, where strong hydrogen bond exists in the closely arranged molecular chains. The SEM image in Figure 2a shows that PVDF particle size is about $200 \mathrm{~nm}$ and uniformly distributed. Figure $2 \mathrm{~b}$ shows the FTIR spectrum of pure PVDF, 873, 1067, 1181, and $1402 \mathrm{~cm}^{-1}$ peaks are assigned to the vibrational features of $\mathrm{C}-\mathrm{C}$ skeleton, $\mathrm{C}-\mathrm{F}$, stretching of $-\mathrm{CF}_{3}$ and deformation of $-\mathrm{CH}_{2}$, respectively $[25,26]$.
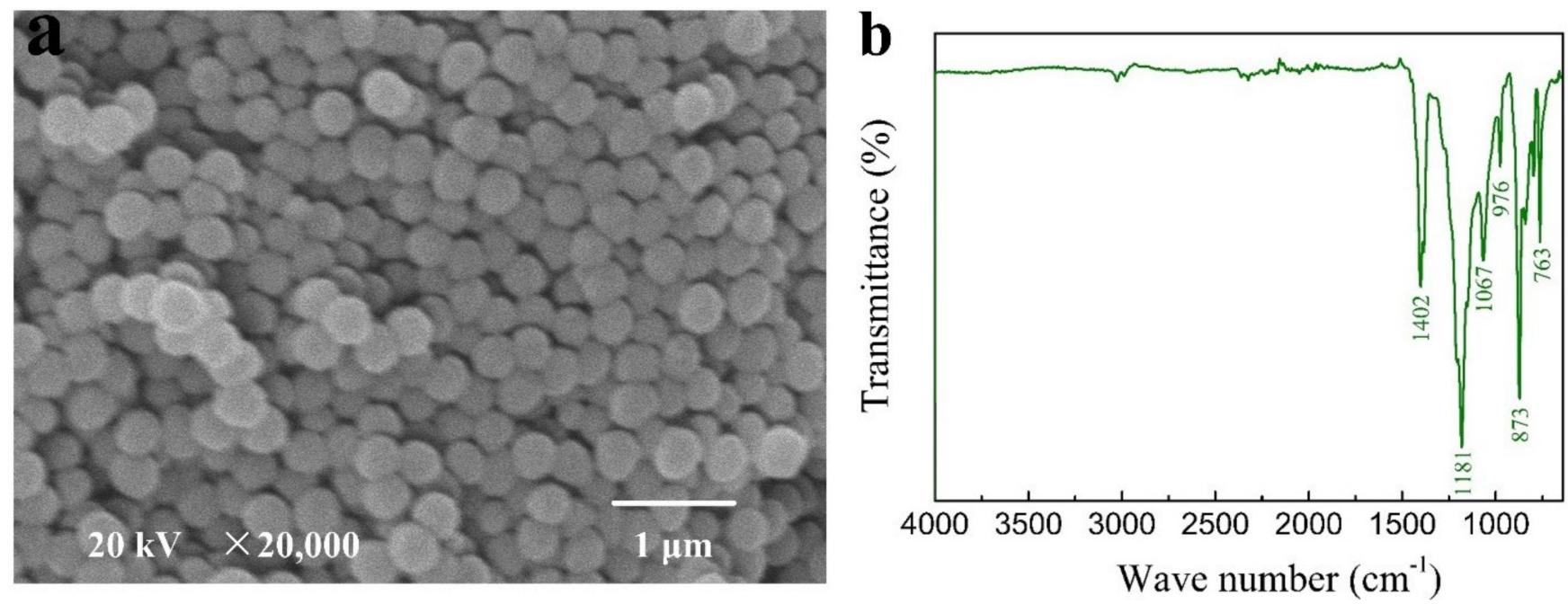

Figure 2. SEM image (a) and FTIR spectrum (b) of polyvinylidene fluoride (PVDF).

\subsection{Methods for Preparing Samples}

PVDF was fully dissolved with organic solvent to form a PVDF solution. A certain amount of dried CM was weighed and uniformly mixed with the prepared PVDF solution to obtain a mixture. The PVDF content was defined as the mass ratio of PVDF to CM, and its values were 4, 8, 10, and $12 \mathrm{wt} \%$; PVDF content of $0 \mathrm{wt} \%$ was also considered for comparison purposes (denoted as M-4, M-8, M-10, M-12, and M-0, respectively). In this study, the compaction degree, dry density, and the organic solvent content of each sample were $96 \%, 2.01 \mathrm{~g} / \mathrm{cm}^{3}$, and $20 \%$, respectively. The sample preparation process and reinforcement ideas are shown in Figure 3. 


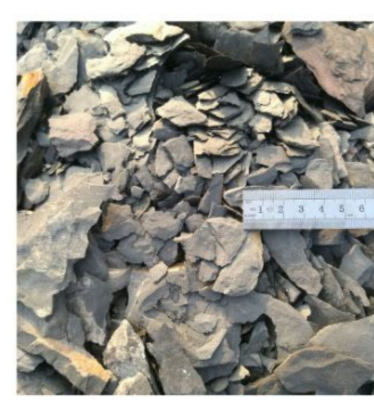

$\mathrm{CM}$

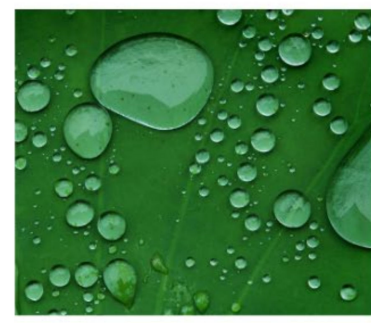

Lotus leaf effect
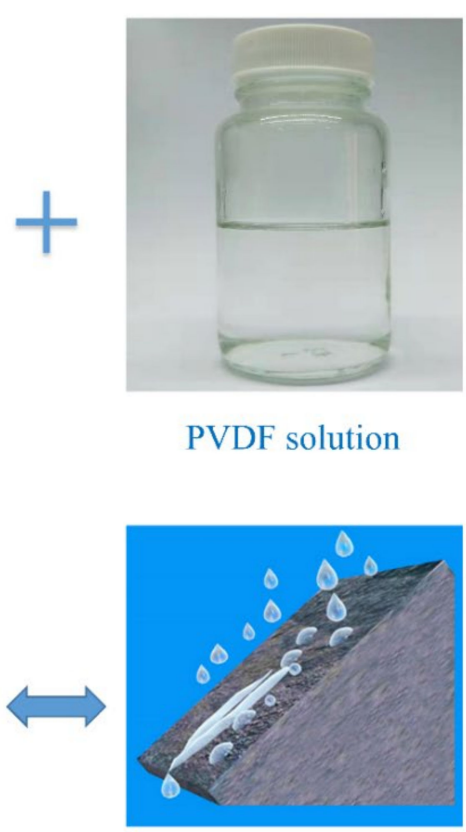

Improve the stability of $\mathrm{CM}$ slope

\section{Rainy seasons}
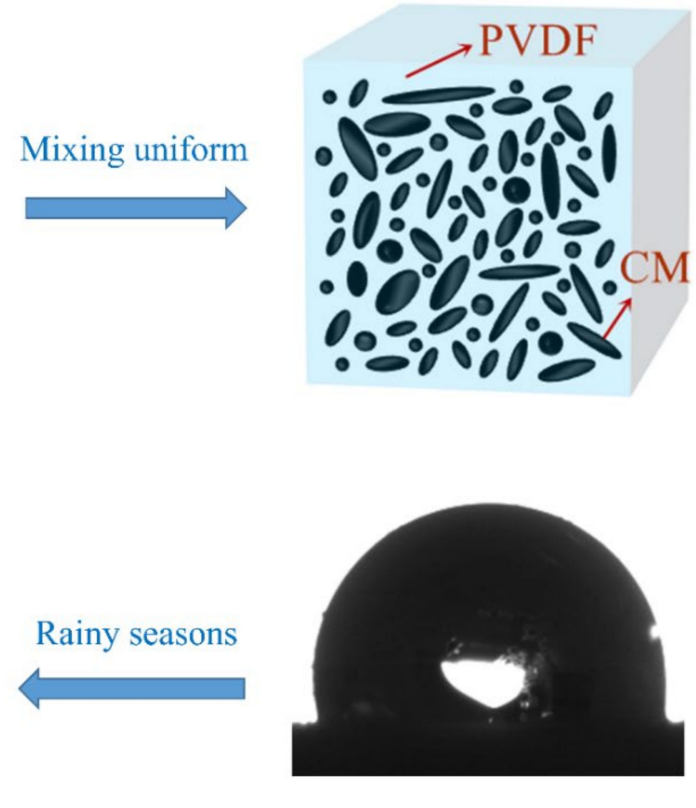

Good hydrophobicity

Figure 3. Schematic diagram of hydrophobic material (i.e., PVDF)-modified CM.

\subsection{Analytical Methods}

\subsubsection{Contact Angle Tests}

Contact angles of PVDF-MCM with different PVDF contents were measured by the mercury intrusion method. A certain amount of mixture was weighed, and the sample was prepared by static pressure method, which had a diameter of $61.8 \mathrm{~mm}$ and a height of $20 \mathrm{~mm}$. The tests were conducted on the Mercury Porosimeter (SDC-350 contact angle measuring instrument). An initial droplet volume of $1 \mu \mathrm{L}$ and a photo frequency of 150 frames per second were applied in the tests. The contact angle tests were repeated three times for each sample, and the average values were taken for subsequent analyses.

\subsubsection{Mechanical Tests}

Unconfined compressive strength (UCS) test is one of the engineering properties of embankment fillers. UCS test is performed to study the effect of PVDF on the compressive strength of modified CM (MCM). The UCS samples were prepared following these procedures: (i) A certain mass of mixture was poured into a steel mold in three layers, and each layer was compacted using the static compaction method to ensure the integrity of the sample, and at the same time, the layers were lapped. (ii) After compaction, both ends of the sample were flattened, then the mold was removed to form a sample with a diameter of $50 \mathrm{~mm}$ and a height of $100 \mathrm{~mm}$. (iii) Because the melting point of PVDF is about $160^{\circ} \mathrm{C}[26,27]$, the samples were dried for $6 \mathrm{~h}$ at $140{ }^{\circ} \mathrm{C}$ and for $2 \mathrm{~h}$ at $160^{\circ} \mathrm{C}$, then cooled down to the room temperature to achieve the best molding effect. (iv) The samples were placed in a standard room (the temperature is $20 \pm 2{ }^{\circ} \mathrm{C}$ and the relative humidity is $\geq 95 \%$ ) for curing. The curing periods were $0,3,7,14,28$ days for durability test. UCS test was conducted in accordance with the Chinese standard "Test methods of soils for highway engineering" [28]. The test instrument was an electronic universal testing machine, and the tests were conducted at an axial strain rate of $1 \% / \mathrm{min}$.

TS can directly reflect the mutual attraction between soil particles and the cohesion of agglomerate materials [29]. The production of tensile sample is to press a certain amount of mixture at one time, and then get it through the same drying steps as UCS and measure it by the direct test method. According to Nahlawi et al. [30], Li et al. [31], and Huang et al. [32], 
the tensile testing device was improved, and an " 8 " type loading fixture was designed. The tensile testing device and sample sizes are shown in Figure 4. The TS durability test is the same as the UCS curing conditions and periods.

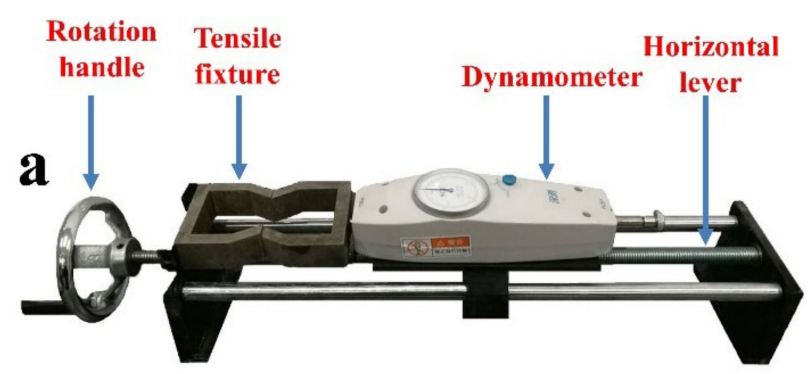

b

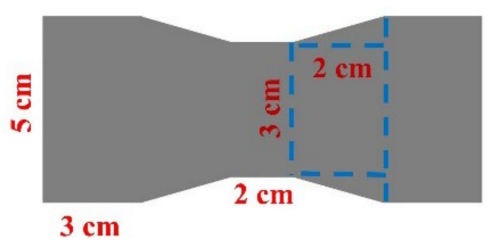

Figure 4. Device (a) and sample dimension (b) for tensile testing.

\subsubsection{Microscopic and Compositional Tests}

XRD, FTIR, SEM, and XRF tests were carried out on PVDF-MCM samples of M-0 and M-10, both of which were at a curing age of $0 \mathrm{~d}$. In SEM tests, typical test blocks with fracture surface about $1 \mathrm{~cm}^{2}$ of unconfined compressive samples were taken [33].

\section{Results and Discussion}

\subsection{Contact Angle}

The time-dependent contact angle is analyzed in Figure 5. Figure 5a presents the optical images of M-0 after dropping $2 \mathrm{~mL}$ pure water on the surface for 0,5 , and $10 \mathrm{~min}$, where the water droplets quickly penetrate deep into the sample within $10 \mathrm{~min}$. Figure $5 \mathrm{~b}$ further shows when the PVDF content is $0 \mathrm{wt} \%$, the droplet almost penetrates into the sample at $1500 \mathrm{~ms}$; while, when PVDF content is $10 \mathrm{wt} \%$, the contact angle of droplet is stable at $103.95^{\circ}$ at $5 \mathrm{~min}$. Figure $5 \mathrm{c}$ shows images of M-10 after dropping $2 \mathrm{~mL}$ pure water on the surface for 0,30 , and $60 \mathrm{~min}$, where the modified sample still retain its hydrophobicity after $60 \mathrm{~min}$.

The contact angles of the modified CM with different PVDF contents in the initial state and stable state are shown in Figure 5d. It can be seen that with the increase of PVDF content, the initial contact angles increase gradually, reaching $98.23^{\circ}$ when the PVDF content is $4 \mathrm{wt} \%$. The stable contact angle of M-4 is almost unchanged compared to M-0. However, the stable contact angle increases rapidly with the increase of PVDF content, reaching $103.95^{\circ}$ when the PVDF content is $10 \mathrm{wt} \%$, where the corresponding initial contact angle is $123.85^{\circ}$. When the contact angle is larger than $90^{\circ}$, it means that the modified CM changes from hydrophilic to hydrophobic material [34]. The time-dependent contact angle is further analyzed.

Polymeric coating techniques are widely applied for tuning the surface properties, e.g., styrene-acrylic emulsion-modified weak rock presents a contact angle of $80^{\circ}$ [19]. Our result shows that the PVDF modification on CM has successfully made the composite CM into hydrophobic material with good retention of hydrophobicity. 


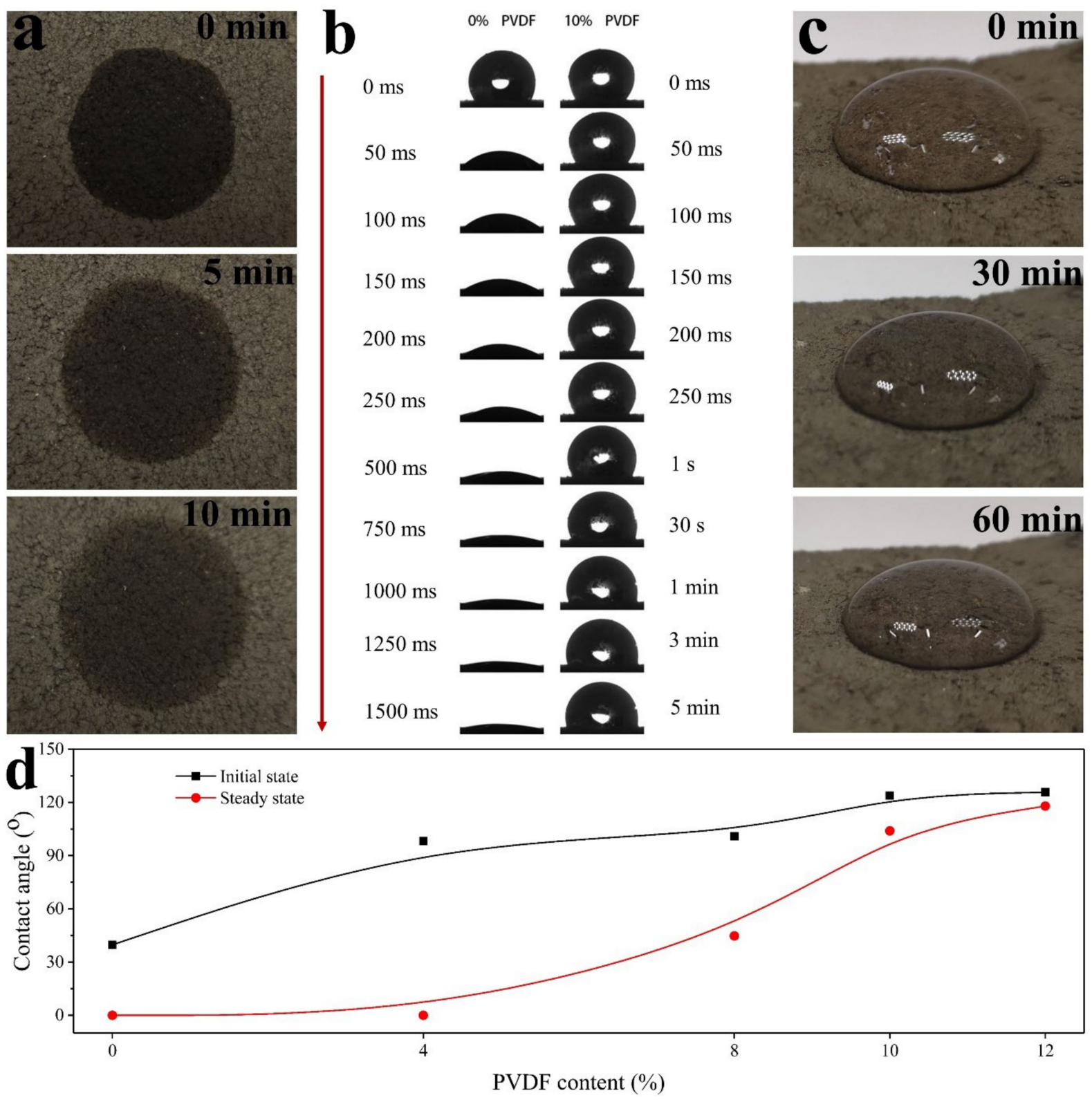

Figure 5. Wettability of PVDF-modified carbonaceous mudstone (PVDF-MCM). Water droplet (a,c) and contact angle (b) evolution on M-0 (a) and M-10 (c); (d) Contact angles of the modified CM with different PVDF contents.

\subsection{Mechanical Strength}

The measured mechanical strength is shown in Figure 6. Figure 6a shows the UCS results of PVDF-MCM. UCS increases with the increase of PVDF content, reaching a maximum of 4.07 MPa when the PVDF content is $8 \mathrm{wt} \%$, and then shows a decrease of $5 \%$ to $3.88 \mathrm{MPa}$ when the PVDF content is $10 \mathrm{wt} \%$. This shows that PVDF has an adverse effect on UCS of CM when its content exceeds $8 \mathrm{wt} \%$. Figure $6 \mathrm{~b}$ shows the TS results of PVDF-MCM. The M-0 samples break and lose their integrity once they are slightly touched, and the TS is considered to be $0 \mathrm{MPa}$. With the increase of the PVDF content, the TS increases significantly. When the PVDF content is $10 \mathrm{wt} \%$, the TS is $1.47 \mathrm{MPa}$, and when the PVDF content is $12 \mathrm{wt} \%$, the TS is $1.96 \mathrm{MPa}$. When the PVDF content does not exceed $12 \%$, PVDF has a positive effect on the TS of the CM. 

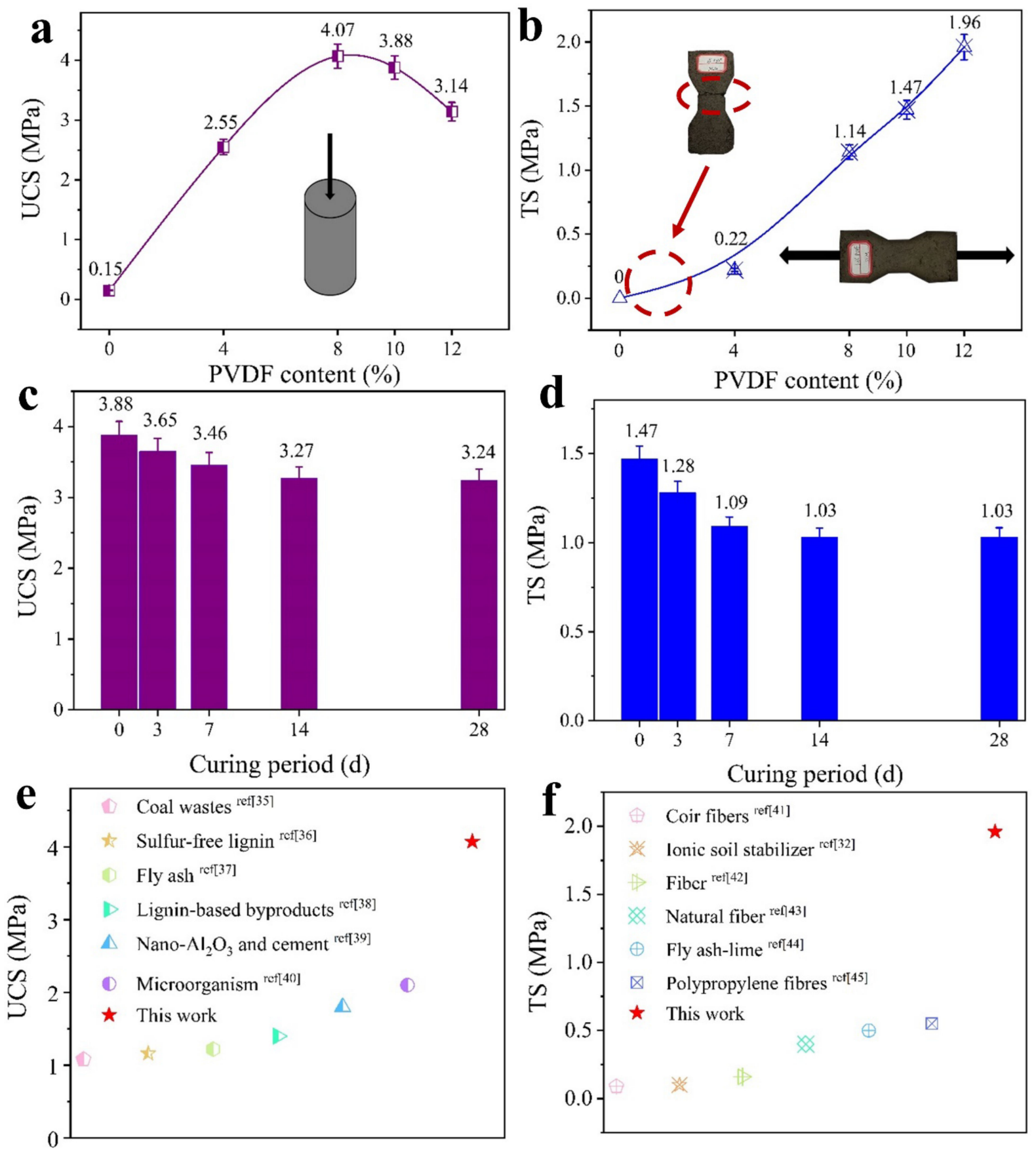

Figure 6. Mechanical properties of PVDF-MCM. Unconfined compressive strength (UCS) (a) and tensile strength (TS) (b) of PVDF-MCM with different contents; Influence of curing period on UCS (c) and TS (d) for M-10; Optimum UCS (e) and TS (f) for several reinforcement materials.

The relation between the durability and contact angle of M-10 is presented in Figure $6 c, d$. Figure $6 c$ shows that in the early and middle stages of curing (i.e., 0, 3, $7 \mathrm{~d}$ ), the UCS value is reduced by about 5\% in turn, and in the later stage of curing (i.e., 14 and $28 \mathrm{~d}$ ), the UCS is stable at $3.24 \mathrm{MPa}$, with $84 \%$ of the initial value retained. Figure $6 \mathrm{~d}$ shows that in the early and middle stages of curing (i.e., 0 , 3, and $7 \mathrm{~d}$ ), TS is reduced by about $10 \%$ in turn, in the later stage of curing (i.e., 14 and $28 \mathrm{~d}$ ), TS is stabilized at $1.03 \mathrm{MPa}$, with $70 \%$ of the initial value retained. These indicate that the high humidity at the pre-mid stage of curing have certain adverse effects on the UCS and TS of PVDF-MCM. Nevertheless, the UCS is stabilized after $14 \mathrm{~d}$ and is still 21.6 times higher than M-0, and the TS is infinite times higher than M-0. 
The optimal UCS values of several modified soils are listed in Figure 6e [35-40], where the UCS of PVDF-MCM in our work is very prominent. On the other hand, the TS values of many modified soils does not exceed 0.5 MPa under the corresponding optimal conditions [32,41-45]; However, in our work, the TS of PVDF-MCM can reach $\sim 2 \mathrm{MPa}$ (Figure 6f) [46]. The results show that the PVDF-MCM has good mechanical properties, and the influence of humidity on the strength of PVDF-MCM can be efficiently alleviated.

\subsection{Microstructure and Composition}

Figure 7 shows the microstructure of M-0 ( $a$ and b) and M-10 (c and d) before curing [47]. It can be seen from Figure $7 \mathrm{a}, \mathrm{b}$ that the $\mathrm{CM}$ particles have obvious boundaries and smooth and flat surfaces, but with a large number of large pores. Comparing Figure $7 \mathrm{a}, \mathrm{b}$ with Figure $7 \mathrm{c}, \mathrm{d}$, it is clear that the particles are interlaced and overlapped, and their boundaries become blurred. PVDF-MCM particles have binder on the surface and between the particles, the pores of the CM are filled, and the whole structure is denser [48]. The pore size distribution (PSD) curve in Figure 8a obtained by the mercury intrusion porosimetry (MIP) [47] shows the pore diameter of samples are concentrated in the range of 1-3 $\mu \mathrm{m}$. With the increase of PVDF content, CM particles bond more closely, which makes the pore diameter corresponding to the peak value of PSD curve show a gradually decreasing trend. The XRF results of M-0 and M-10 shown in Table 1 further confirm the binder composition, where the content of $\mathrm{F}$ in the modified CM increased significantly with $10 \mathrm{wt} \%$ PVDF as designed.
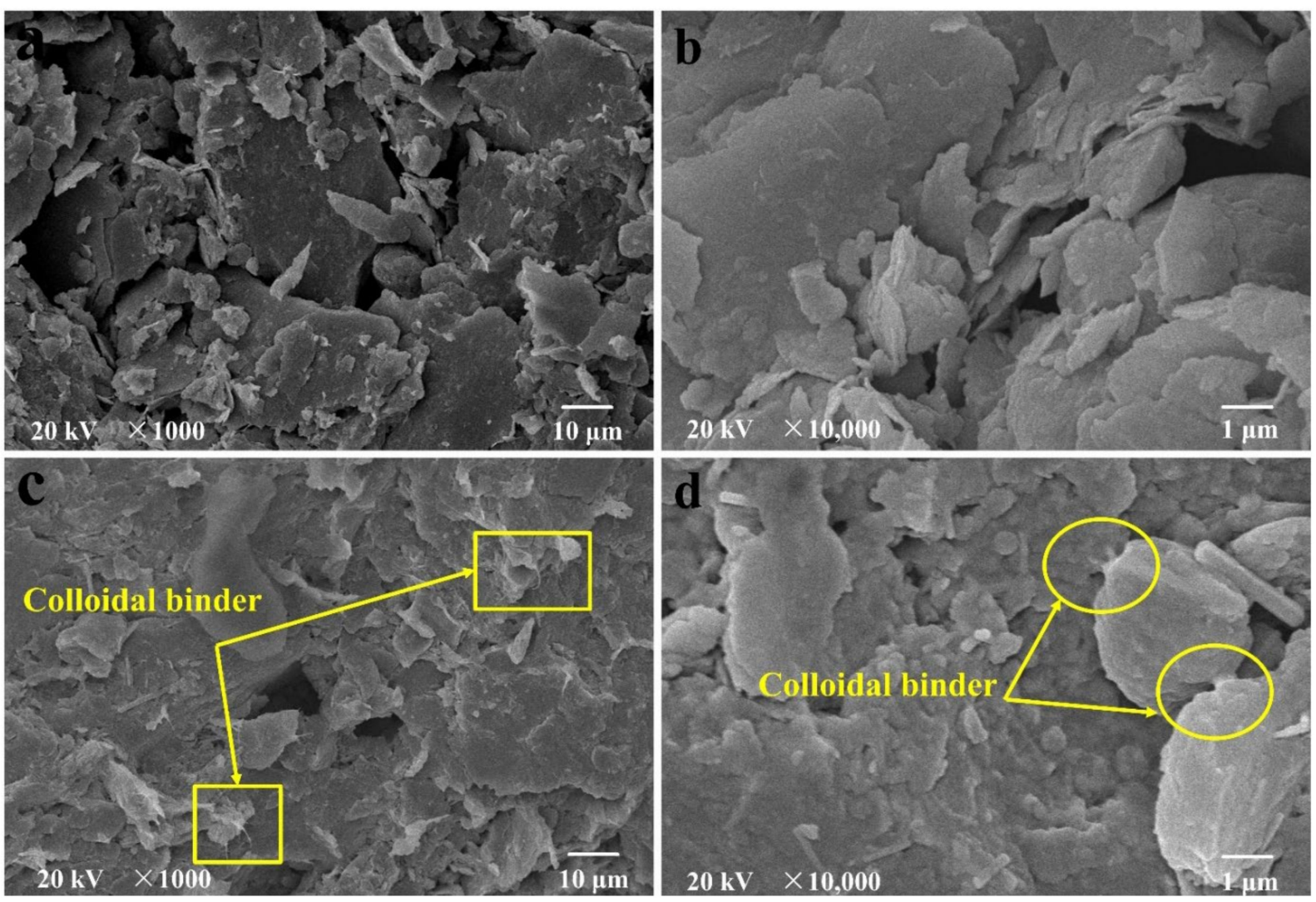

Figure 7. The microstructure of $\mathrm{M}-0(\mathbf{a}, \mathbf{b})$ and $\mathrm{M}-10(\mathbf{c}, \mathbf{d})$ before curing. 

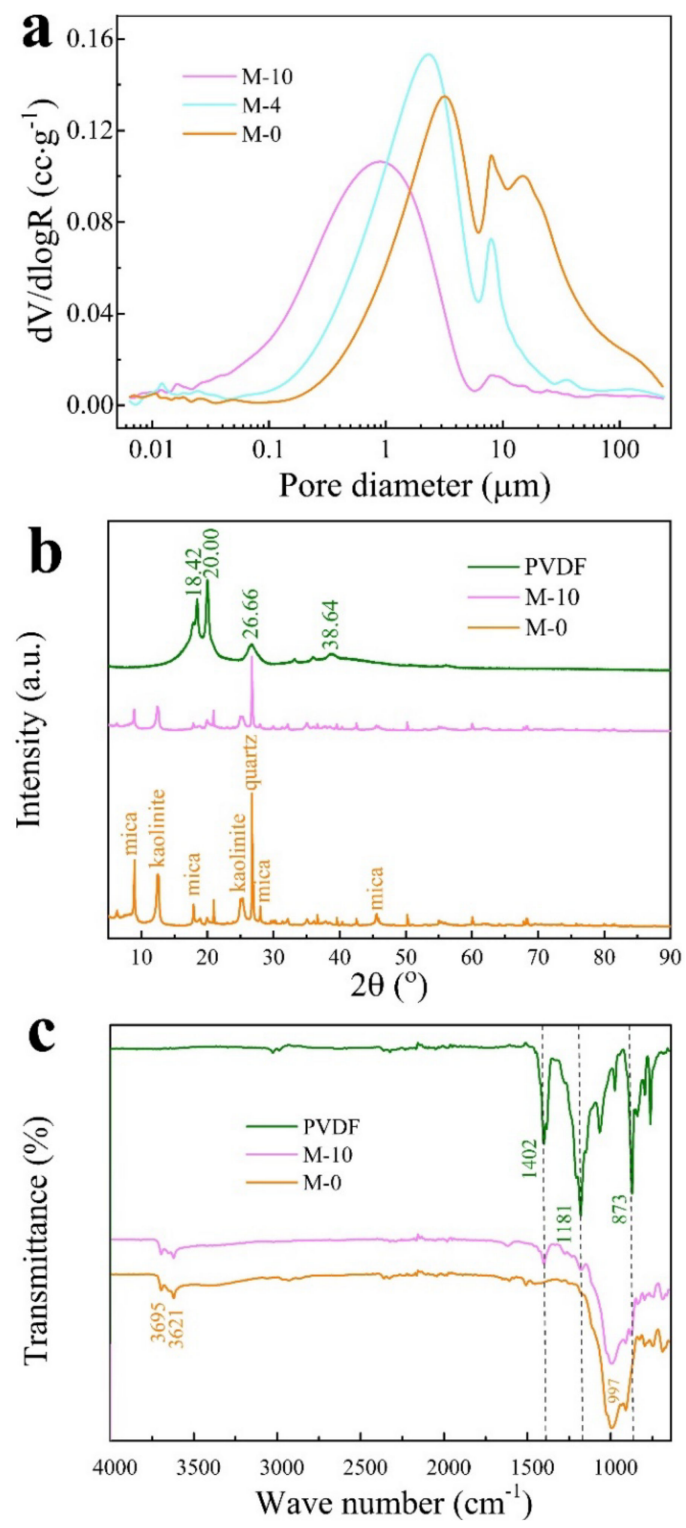

Figure 8. Pore size distribution (PSD) (a) of M-0, M-4 and M-10; XRD (b) and FTIR (c) of PVDF, M-0 and $\mathrm{M}-10$.

Table 1. XRF of M-0 and M-10.

\begin{tabular}{ccccccccccc}
\hline Samples & $\mathbf{O}$ & $\mathbf{S i}$ & $\mathbf{A l}$ & $\mathbf{F e}$ & $\mathbf{K}$ & $\mathbf{F}$ & $\mathbf{C a}$ & $\mathbf{S}$ & $\mathbf{M g}$ & Others \\
\hline M-0 & 43.40 & 22.48 & 13.98 & 4.17 & 3.31 & 0.00 & 1.76 & 0.79 & 0.64 & 9.47 \\
M-10 & 40.30 & 21.39 & 13.21 & 4.55 & 3.08 & 2.94 & 1.76 & 0.78 & 0.62 & 11.37 \\
\hline
\end{tabular}

XRD analysis was carried out on PVDF, M-0, and M-10 to determine the phase of PVDF-MCM. The results are shown in Figure $8 \mathrm{~b}$. The diffraction angles $2 \theta$ of $18.42^{\circ}, 20.00^{\circ}$, $26.66^{\circ}$, and $38.64^{\circ}$, are assigned to the characteristic $\alpha$ phase of PVDF [49]. The mineral compositions of M-0 are mainly quartz, pyrite, kaolinite, siderite, mica, calcite, hemihydrate gypsum. For M-10, it consists of the above mineral phases and the introduced PVDF phase. Hence, there is no formation of new minerals observed during the processing, where the quartz content is the maximum difference but within 1\%. Typical diffraction peaks of mica and kaolinite are clearly revealed in $\mathrm{M}-10$, comparing to $\mathrm{M}-0$, the diffraction peaks of $8.92^{\circ}, 12.43^{\circ}, 17.87^{\circ}, 24.97^{\circ}, 27.93^{\circ}, 45.54^{\circ}$ show broadening, indicating the reduction in crystalline size of $\mathrm{CM}$ after processing. In M-10 there are also red-shifts of $0.06^{\circ}, 0.04^{\circ}$, 
$0.08^{\circ}, 0.06^{\circ}$ for $8.92^{\circ}, 17.87^{\circ}, 27.93^{\circ}, 45.54^{\circ}$ peaks in mica phase and $0.06^{\circ}, 0.06^{\circ}$ for $12.43^{\circ}$, $24.97^{\circ}$ in kaolinite phase suggest the increase of the interplanar spacings in CM particles, which is attributed to the change of interplanar spacings due to the introduction of PVDF in CM [49]. In order to further explore the interaction between PVDF and CM, the molecular structure and chemical properties of PVDF-MCM are then analyzed.

Figure $8 \mathrm{c}$ presents the FTIR results of pure PVDF, M-0, and M-10. It can be seen that M-0 and M-10 mainly contain a $3695 \mathrm{~cm}^{-1}$ internal surface hydroxyl vibration peak, which is located between the Al-O octahedron and $\mathrm{Si}-\mathrm{O}$ tetrahedron, at $3621 \mathrm{~cm}^{-1}$ is an internal hydroxyl vibration peak and the Si-O vibration peak corresponding to $997 \mathrm{~cm}^{-1}[50,51]$. Furthermore, three emerging absorption peaks in the spectrum of M-10, i.e., $1402 \mathrm{~cm}^{-1}$, $1181 \mathrm{~cm}^{-1}$, and $873 \mathrm{~cm}^{-1}$, correspond to the $\mathrm{CH}_{2}, \mathrm{CF}_{3}$, and $\mathrm{C}-\mathrm{C}$ characteristic functional groups of PVDF. The consistent vibrational bands of M-10 with those of the pristine PVDF (Figure 2b) confirm the successful incorporation of the PVDF in CM. Interestingly, the broad vibrational feature at $3300-3500 \mathrm{~cm}^{-1}$ in $\mathrm{M}-0$, due to the intercalated water in CM, is obviously reduced in $\mathrm{M}-10$. This is consistent with the above finding on the change of interlayer distances between layer structures in both mica and kaolinite phases. Hence, by introducing PVDF into the CM system, the interlayer interaction in CM host is altered, which leads to the change of interlayer spacing.

\section{Reinforcement Mechanism}

PVDF solution is mixed with CM to form a hydrophobic structural film, and the loose $\mathrm{CM}$ is combined into a whole to effectively prevent the softening effect of water. The reinforcement mechanism of PVDF modifiers is as follows [19,52-54]:

(i) Waterproof: After the evaporation of organic solvent, PVDF solidifies to form hydrophobic macromolecular polymer layer. It can be entangled with CM to form a network structure layer, which effectively prevents water from infiltrating into the material [55].

(ii) Binding: Fluorinated chain segment shields the polarity of polar groups, which makes the surface of PVDF hydrophobic. At the same time, the surface energy of the PVDF membrane is low, which leads to the poor wettability of the membrane. PVDF has good cementation and can fill the pores of CM, which effectively increases the bond strength of CM particles and solidifies the particles into a new whole [56,57].

(iii) Polymerization: PVDF and CM have good adhesion after mixing, because PVDF can be polymerized to form a polymeric layer. The oxygen-containing functional groups on the surface of CM particles may form chemical bonds with PVDF, which may enhance the mechanical strength of CM matrix (Figure 9). After modification, it has high strength and good hydrophobic properties.

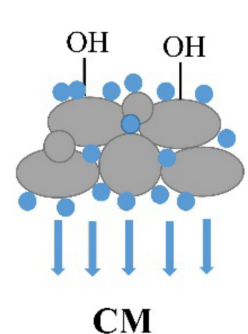

CM

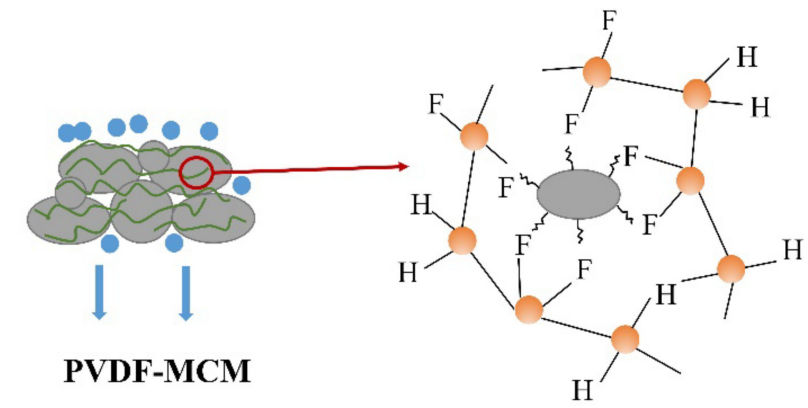

IPermeate water $\rightarrow \quad-\mathrm{OH}$

$\mathrm{C} \sim \mathrm{PVDF}$

Figure 9. Schematic diagram of reforcement mechanism for PVDF-MCM. 


\section{Conclusions}

In this work, a hydrophobic material, PVDF, was innovatively used to modify the mechanical strength and other properties of $\mathrm{CM}$ which was prone to continuous disintegration in water. The SEM images and FTIR results showed that PVDF dispersed uniformly in CM matrix, which might lead to a good strength of PVDF-MCM composites. The UCS and TS of PVDF-MCM were enhanced to $4.07 \mathrm{MPa}$ and $1.96 \mathrm{MPa}$, respectively, both of which were much higher than those of pristine $\mathrm{CM}$ matrix. The experimental result of contact angle was much higher than $90^{\circ}$, implying an excellent hydrophobicity of PVDF-MCM composites. Importantly, the UCS and TS of PVDF-MCM are still high even in high humidity conditions. All results showed that PVDF-MCM had good hydrophobicity and mechanical properties. The modification mechanism was also analyzed and summarized. The PVDF-MCM mechanism revealed in this paper can provide some references for the application of new and non-traditional modifiers such as polymers, and the mechanism needs further verification by more experimental studies. The good performance and low cost of PVDF make it a promising candidate for stable CM slope application.

Author Contributions: Conceptualization, H.F. and C.J.; methodology, H.F. and C.J.; software, C.C.; validation, H.F., C.C., H.Z., D.Y., Q.-F.G., L.Z. and C.J.; resources H.F. and C.J.; data curation, C.C.; writing—original draft preparation, C.C.; writing—review and editing, H.F., Q.-F.G., D.Y. and C.J.; supervision, H.F. and C.J.; project administration, H.F.; funding acquisition, H.F. All authors have read and agreed to the published version of the manuscript.

Funding: This research were funded by the National Natural Science Foundation of China, grant number 51878070, 51838001; the Research and Development Projects in Key Fields of Hunan Province, China, grant number 2019SK2171 and the Postgraduate Research and Innovation Projects in Hunan Province, grant number CX20190634.

Institutional Review Board Statement: Not applicable.

Informed Consent Statement: Not applicable.

Data Availability Statement: Both experimental and fitting data are available from the corresponding author.

Acknowledgments: This work was supported by the National Natural Science Foundation of China (51878070, 51838001), the Research and Development Projects in Key Fields of Hunan Province, China (2019SK2171) and the Postgraduate Research and Innovation Projects in Hunan Province (CX20190634).

Conflicts of Interest: The authors declare no conflict of interest.

\section{References}

1. Liu, B.; Yang, H.; Karekal, S. Effect of water content on argillization of mudstone during the tunnelling process. Rock Mech. Rock Eng. 2020, 53, 799-813. [CrossRef]

2. Zhang, F.; Xie, S.Y.; Hu, D.W.; Shao, J.F.; Gatmiri, B. Effect of water content and structural anisotropy on mechanical property of claystone. Appl. Clay Sci. 2012, 69, 79-86. [CrossRef]

3. Zhou, C.Y.; Deng, Y.M.; Tan, X.S.; Liu, Z.Q.; Shang, W.; Zhan, S. Experimental research on the softening of mechanical properties of saturated softrocks and application. Chin. J. Rock Mech. Eng. 2005, 24, 33-38. (In Chinese)

4. Cheng, Q.; Gao, L.; Zuo, X.; Zhong, F. Statistical analyses of spatial and temporal variabilities in total, daytime, and nighttime precipitation indices and of extreme dry/wet association with large-scale circulations of Southwest China, 1961-2016. Atmos. Res. 2019, 219, 166-182. [CrossRef]

5. Fu, H.Y.; Liu, J.; Zeng, L.; Xiao, L.Y.; Hou, P. Disintegration characteristics of carbonaceous mudstone under loading and wet-dry cycles. China J. Highw. Transp. 2019, 32, 22-31. (In Chinese)

6. Donati, D.; Stead, D.; Lato, M.; Gaib, S. Spatio-temporal characterization of slope damage: Insights from the Ten Mile Slide, British Columbia, Canada. Landslides 2020, 17, 1037-1049. [CrossRef]

7. Ministry of Land and Resources of the People's Republic of China. National 13th Five-Year Plan for the Prevention and Control of Geological Disasters. Available online: http:/ / www.cgs.gov.cn/tzgg/tzgg/201701/t20170103_420412.html (accessed on 3 January 2017). (In Chinese)

8. Wang, Y.; Zhang, G.; Wang, A. Block reinforcement behavior and mechanism of soil slopes. Acta Geotech. 2018, 13, 1155-1170. [CrossRef] 
9. Turner, J.P.; Jensen, W.G. Landslide stabilization using soil nail and mechanically stabilized earth walls: Case study. J. Geotech. Geoenviron. 2005, 131, 141-150. [CrossRef]

10. Zhang, G.; Wang, L.; Wang, Y. Pile reinforcement mechanism of soil slopes. Acta Geotech. 2017, 12, 1035-1046. [CrossRef]

11. Niu, H. The environmental effect of application of chemical grouting in slope reinforcement. Ekoloji Derg. 2019, 28, 3345-3350.

12. Bahar, R.; Benazzoug, M.; Kenai, S. Performance of compacted cement-stabilised soil. Cem. Concr. Compos. 2004, 26, 811-820. [CrossRef]

13. Saleh, S.; Yunus, N.Z.M.; Ahmad, K.; Ali, N. Improving the strength of weak soil using polyurethane grouts: A review. Constr. Build. Mater. 2019, 202, 738-752. [CrossRef]

14. Najim, K.B.; Mahmod, Z.S.; Atea, A.K.M. Experimental investigation on using Cement Kiln Dust (CKD) as a cement replacement material in producing modified cement mortar. Constr. Build. Mater. 2014, 55, 5-12. [CrossRef]

15. Wu, H.; Li, Z.; Song, W.; Zou, J.; Liu, W.; Yu, J. Experimental study on moisture susceptibility of subgrade soil with superabsorbent polymers. J. Mater. Civ. Eng. 2019, 31, 04019120. [CrossRef]

16. Rezaeimalek, S.; Huang, J.; Bin-Shafique, S. Evaluation of curing method and mix design of a moisture activated polymer for sand stabilization. Constr. Build. Mater. 2017, 146, 210-220. [CrossRef]

17. Rashid, A.S.A.; Latifi, N.; Meehan, C.L.; Manahiloh, K.N. Sustainable improvement of tropical residual soil using an environmentally friendly additive. Geotech. Geol. Eng. 2017, 35, 2613-2623. [CrossRef]

18. Latifi, N.; Horpibulsuk, S.; Meehan, C.L.; Majid, M.Z.A.; Tahir, M.M.; Mohamad, E.T. Improvement of problematic soils with biopolymer-an environmentally friendly soil stabilizer. J. Mater. Civ. Eng. 2016, 29, 4016204. [CrossRef]

19. Yao, D.; Qian, G.; Liu, J.; Yao, J. Application of polymer curing agent in ecological protection engineering of weak rock slopes. Appl. Sci. 2019, 9, 1585. [CrossRef]

20. Peng, Y.; Xiao, D.; Yu, G.; Feng, Y.; Li, J.; Zhao, X.; Tang, Y.; Wang, L.; Zhang, Q. Effect of an eco-friendly o/w emulsion stabilized with amphiphilic sodium alginate derivatives on lambda-cyhalothrin adsorption-desorption on natural soil minerals. J. Environ. Sci. 2019, 78, 230-238. [CrossRef]

21. Liu, J.; Chen, Z.; Kanungo, D.P.; Song, Z.; Bai, Y.; Wang, Y.; Li, D.; Qian, W. Topsoil reinforcement of sandy slope for preventing erosion using water-based polyurethane soil stabilizer. Eng. Geol. 2019, 252, 125-135. [CrossRef]

22. Andavan, S.; Kumar, B.M. Case study on soil stabilization by using bitumen emulsions-A review. Mater. Today Proc. 2020, 22, 1200-1202. [CrossRef]

23. Nthunya, L.N.; Gutierrez, L.; Derese, S.; Nxumalo, E.N.; Verliefde, A.R.; Mamba, B.B.; Mhlanga, S.D. A review of nanoparticleenhanced membrane distillation membranes: Membrane synthesis and applications in water treatment. J. Chem. Technol. Biotechnol. 2019, 94, 2757-2771. [CrossRef]

24. Kang, G.D.; Cao, Y.M. Application and modification of poly (vinylidene fluoride) (PVDF) membranes-A review. J. Membr. Sci. 2014, 463, 145-165. [CrossRef]

25. Hou, D.; Lin, D.; Ding, C.; Wang, D.; Wang, J. Fabrication and characterization of electrospun superhydrophobic PVDFHFP/SiNPs hybrid membrane for membrane distillation. Sep. Purif. Technol. 2017, 189, 82-89. [CrossRef]

26. Cai, M.; He, H.; Zhang, X.; Yan, X.; Li, J.; Chen, F.; Ding, Y.; Ning, X. Efficient synthesis of PVDF/PI side-by-side bicomponent nanofiber membrane with enhanced mechanical strength and good thermal stability. Nanomaterials 2019, 9, 39. [CrossRef]

27. Doshi, K.; Trivedi, Y.; Ray, P.; Singh, P.S. Degumming of crude vegetable oil by membrane separation: Probing structureperformance and stability of PVDF membranes. Sep. Sci. Technol. 2019, 54, 360-369. [CrossRef]

28. Ministry of Transport of the People's Republic of China. JTG E40-2007 Test Methods of Soils for Highway Engineering; China Communications Press: Beijing, China, 2007.

29. Schubert, H. Tensile strength of agglomerates. Powder Technol. 1975, 11, 107-119. [CrossRef]

30. Nahlawi, H.; Chakrabarti, S.; Kodikara, J. A direct tensile strength testing method for unsaturated geomaterials. Geotech. Test. J. 2004, 27, 356-361.

31. Li, H.D.; Tang, C.S.; Cheng, Q.; Li, S.J.; Gong, X.P.; Shi, B. Tensile strength of clayey soil and the strain analysis based on image processing techniques. Eng. Geol. 2019, 253, 137-148. [CrossRef]

32. Huang, W.; Xiang, W.; Wang, J.E.; Cheng, C.J.; Liu, Q.B. Development and application of digital image processing technology based soil tensile apparatus. Rock Soil Mech. 2018, 39, 3486-3495. (In Chinese)

33. Gao, Q.F.; Dong, H.; Huang, R.; Li, Z.F. Structural characteristics and hydraulic conductivity of an eluvial-colluvial gravelly soil. Bull. Eng. Geol. Environ. 2019, 78, 5011-5028. [CrossRef]

34. Jin, J.; Zhao, X.L.; Du, Y.H.; Ding, M.; Xiang, C.J.; Yan, N.; Jia, C.K.; Han, Z.; Sun, L.D. Nanostructured three-dimensional percolative channels for separation of oil-in-water emulsions. iScience 2018, 6, 289-298. [CrossRef] [PubMed]

35. Afrakoti, M.T.P.; Choobbasti, A.J.; Ghadakpour, M.; Kutanaei, S.S. Investigation of the effect of the coal wastes on the mechanical properties of the cement-treated sandy soil. Constr. Build. Mater. 2020, 239, 117848. [CrossRef]

36. Liu, Y.; Zheng, W.; Wang, Q.; Cao, C.; Chang, M.; Rocchi, I. Evaluating sulfur-free lignin as a sustainable additive for soil improvement against frost resistance. J. Clean. Prod. 2020, 251, 119504. [CrossRef]

37. Liang, S.; Chen, J.; Guo, M.; Feng, D.; Liu, L.; Qi, T. Utilization of pretreated municipal solid waste incineration fly ash for cement-stabilized soil. Waste Manag. 2020, 105, 425-432. [CrossRef] [PubMed]

38. Yang, B.; Zhang, Y.; Ceylan, H.; Kim, S.; Gopalakrishnan, K. Assessment of soils stabilized with lignin-based byproducts. Transp. Geotech. 2018, 17, 122-132. [CrossRef] 
39. Fu, H.Y.; Liu, J.; Zha, H.Y. Study of the strength of disintegrated carbonaceous mudstone modified with nano- $\mathrm{Al}_{2} \mathrm{O}_{3}$ and cement. J. Nanosci. Nanotechnol. 2020, 20, 4839-4845. [CrossRef]

40. Cheng, L.; Shahin, M.A.; Mujah, D. Influence of key environmental conditions on microbially induced cementation for soil stabilization. J. Geotech. Geoenviron. 2017, 143, 04016083. [CrossRef]

41. Anggraini, V.; Asadi, A.; Huat, B.B.; Nahazanan, H. Effects of coir fibers on tensile and compressive strength of lime treated soft soil. Measurement 2015, 59, 372-381. [CrossRef]

42. Li, Y.; Ling, X.; Su, L.; An, L.; Li, P.; Zhao, Y. Tensile strength of fiber reinforced soil under freeze-thaw condition. Cold Reg. Sci. Technol. 2018, 146, 53-59. [CrossRef]

43. Tran, K.Q.; Satomi, T.; Takahashi, H. Tensile behaviors of natural fiber and cement reinforced soil subjected to direct tensile test. J. Build. Eng. 2019, 24, 100748. [CrossRef]

44. Consoli, N.C.; Rocha, C.G.; Silvani, C. Devising dosages for soil-fly ash-lime blends based on tensile strength controlling equations. Constr. Build. Mater. 2014, 55, 238-245. [CrossRef]

45. Correia, A.A.; Oliveira, P.J.; Custodio, D.G. Effect of polypropylene fibres on the compressive and tensile strength of a soft soil, artificially stabilised with binders. Geotext. Geomembr. 2015, 43, 97-106. [CrossRef]

46. Shen, Z.; Cao, Y.; Fang, L. Experimental investigation of rapid stabilization of soft clay soils using chemical admixtures. Soil Mech. Found. Eng. 2017, 54, 202-210. [CrossRef]

47. Gao, Q.F.; Zhao, D.; Zeng, L.; Dong, H. A pore size distribution-based microscopic model for evaluating the permeability of clay. KSCE J. Civ. Eng. 2019, 23, 5002-5011. [CrossRef]

48. He, Z.M.; Xiang, D.; Liu, Y.X.; Gao, Q.F.; Bian, H.B. Deformation behavior of coarse-grained soil as an embankment filler under cyclic loading. Adv. Civ. Eng. 2020, 2020, 4629105.

49. Sun, Q.; Yang, Z.; Hu, C.; Li, C.; Yan, G.; Wang, Z. Facile preparation of superhydrophobic PVDF microporous membranes with excellent anti-fouling ability for vacuum membrane distillation. J. Membr. Sci. 2020, 605, 118106. [CrossRef]

50. Yu, L.Y.; Xu, Z.L.; Shen, H.M.; Yang, H. Preparation and characterization of $\mathrm{PVDF} \mathrm{SiO}_{2}$ composite hollow fiber UF membrane by sol-gel method. J. Membr. Sci. 2009, 337, 257-265. [CrossRef]

51. Zeng, L.; Ye, J.; Zhang, J.; Liu, J.; Jia, C. A promising SPEEK/MCM composite membrane for highly efficient vanadium redox flow battery. Surf. Coat. Technol. 2019, 358, 167-172. [CrossRef]

52. Liang, S.; Kang, Y.; Tiraferri, A.; Giannelis, E.P.; Huang, X.; Elimelech, M. Highly hydrophilic polyvinylidene fluoride (PVDF) ultrafiltration membranes via postfabrication grafting of surface-tailored silica nanoparticles. ACS Appl. Mater. Interfaces 2013, 5, 6694-6703. [CrossRef]

53. Göbel, L.; Königsberger, M.; Osburg, A.; Pichler, B. Viscoelastic behavior of polymer-modified cement pastes: Insight from downscaling short-term macroscopic creep tests by means of multiscale modeling. Appl. Sci. 2018, 8, 487. [CrossRef]

54. Khosravani, M.R.; Weinberg, K. A review on split Hopkinson bar experiments on the dynamic characterisation of concrete. Constr. Build. Mater. 2018, 190, 1264-1283. [CrossRef]

55. Lv, J.L.; Zhang, G.Q.; Zhang, H.M.; Yang, F.L. Graphene oxide-cellulose nanocrystal (GO-CNC) composite functionalized PVDF membrane with improved antifouling performance in MBR: Behavior and mechanism. Chem. Eng. J. 2018, 352, 765-773. [CrossRef]

56. Wu, C.R.; Tang, W.Y.; Zhang, J.H.; Liu, S.H.; Wang, Z.Y.; Wang, X.; Lu, X.L. Preparation of super-hydrophobic PVDF membrane for MD purpose via hydroxyl induced crystallization-phase inversion. J. Membr. Sci. 2017, 543, 288-300. [CrossRef]

57. Jeschull, F.; Maibach, J.; Edstrom, K.; Brandell, D. On the electrochemical properties and interphase composition of graphite: PVdF-HFP electrodes in dependence of binder content. J. Electrochem. Soc. 2017, 164, 1765-1772. [CrossRef] 